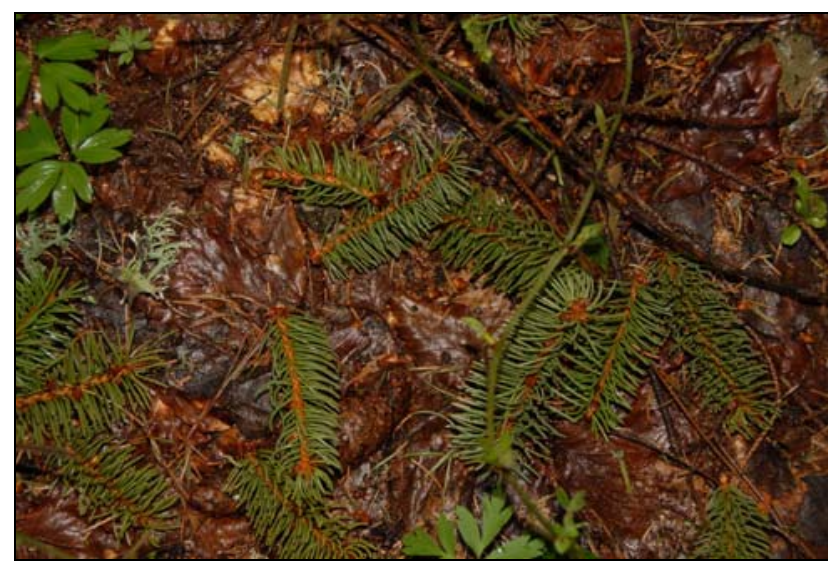

Slika 1: Odgriznjene vejice navadne smreke zaradi navadne veverice

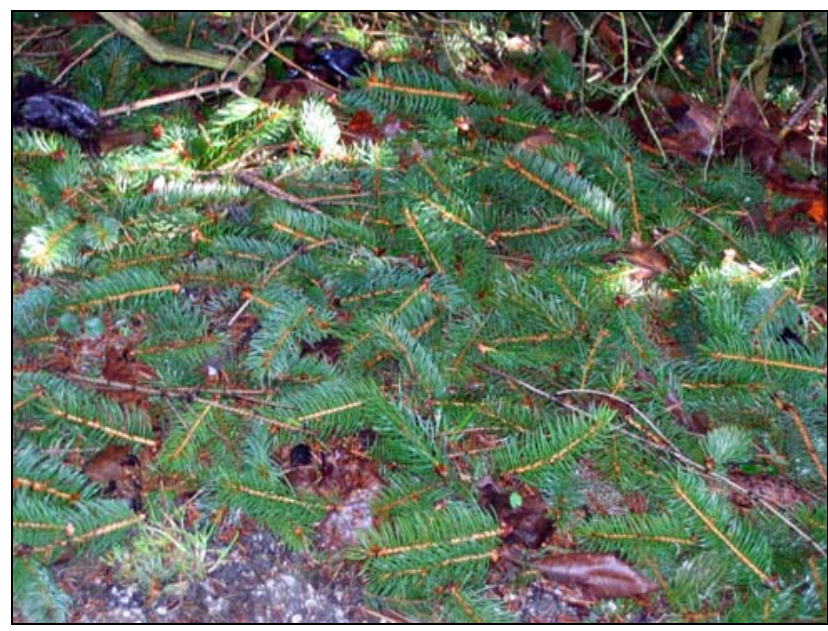

Slika 2: V zimi z debelejšo snežno odejo, lahko pod smrekami naletimo na več $\mathrm{cm}$ deblo plast odgriznjenih vejic, katerim je popke pojedla navadna veverica

\title{
Odmiranje listja puhastega hrasta na Krasu v letu 2008, hrastova list- na pegavost (Dicarpella dryina)
}

\section{Dušan JURC $^{1^{*}}$,Nikica OGRIS $^{1}$, Barbara PIŠKUR $^{1}$, Tine HAUPTMAN ${ }^{1}$, Boštjan KOŠIČEK ${ }^{2}$}

V letu 2008 je bilo listje puhastega hrasta izjemno močno poškodovano na širšem območju med Štorjami, Koprivo in Štanjelom. Enaka znamenja odmiranja smo opazili tudi blizu Podgorja, na hribu Skrbina. Pregled vzorcev v Laboratoriju za varstvo gozdov GIS je pokazal, da je pege na listih in njegovo odmiranje povzročila gliva Dicarpella dryina Belisario \& M.E. Barr (teleomorf). Ker je na odmirajočem listju ob koncu vegetacijske dobe vedno prisoten anamorf, povzročiteljico bolezni običajno navajajo $\mathrm{z}$ imenom anamorfa, to pa je Tubakia dryina (Sacc.) Sutton. Slovenskega imena bolezen doslej ni imela. Predlagamo ime "hrastova listna pegavost", ki to bolezen jasno loči od "rjavenja hrastovih listov", ki ga povzroča gliva Discula quercina (Westend.) Arx, (teleomorf: Apiognomonia quercina (Kleb.) Höhn). O obeh boleznih smo pisali v Gozdarskem vestniku (Jurc, 2006) in spodaj navajamo dopolnjen del prispevka $v$ zvezi s hrastovo listno pegavostjo.

\section{Hrastova listna pegavost: Tubakia dryina (Sacc.) Sutton, anamorf \\ Teleomorf: Dicarpella dryina Belisario \& M.E. Barr}

Taksonomska uvrstitev: Melanconidaceae, Diaporthales (vrtačarji), Sordariomycetidae (trhnobarice), Ascomycetes (mešičkovnice), Ascomycota (zaprtotrosnice), Fungi (glive) (Kirk in sod., 2001)

\section{Oznaka bolezni}

Endofitna gliva, ki povzroča tudi nekroze listja.

\section{Opis glive}

Anamorf Tubakia dryina ima nespolno trosišče posebne oblike, ki ga imenujemo piknotirij (pycnothyrium). Ima obliko drobnega ščitka (scutellum), ki ga kratek podstavek (columella) pritrjuje na površino lista. Ščitek je sestavljen iz rjavih hif $\mathrm{z}$ debelimi stenami, ki radialno izhajajo iz centra ščitka. Hife se razvejujejo in na robu ščitka se koničasto zaključijo tako, da oblikujejo resast rob. Ščitki imajo premer 70-120 $\mu \mathrm{m}$ (slika 4). Podstavek, ki je centralno nameščen pod ščitkom, nosi konidiotvorne celice. Te oblikujejo konidije, ki se nabirajo pod ščitkom in okoli njega. Prosojni konidiji so veliki 8-14 × 6-10 $\mu \mathrm{m}$ (Proffer, 1990). Mikrokonidiji se oblikujejo na piknotiriju, ki še ni dokončno razvit.

Teleomorf je bil opisan šele leta 1991 in se razvije na odmrlem listju naslednjo pomlad.

\section{Opis bolezni}

Gliva povzroča rjave do rdeče rjave nekrotične pege na listih. Premer imajo 0,1-1,5 cm, običajno so okrogle ali oglate, lahko se združujejo in obsegajo večje odmrle površine listov. Odmrlo tkivo ima temnejši rob na meji z zdravimi tkivi lista, v pegah so prav tako včasih opazni tanki temni koncentrični kolobarji (sliki 2 in 3). Če se bolezen razvija med rastjo mladih listov so ti lahko deformirani. Na spodnji strani listov, včasih pa na obeh, s prostim očesom komaj opazimo drobne, črne piknotirije. Nekrotične pege se pogosto nadaljujejo $\mathrm{V}$ zdravo tkivo lista $\mathrm{z}$ rahlo klorozo, tako, da je rjava pega centralno nameščena $\mathrm{v}$ večji rumen krog na listu.

Med hrasti najpogosteje prizadene graden (Quercus petraea) (Butin, 1995). Poleg hrastov gliva lahko povzroča bolezen na javorih (Acer spp.), kostanjih (Castanea spp.), brestih (Ulmus spp.) in še na nekaterih tujih drevesnih vrstah. Trosi, ki so se razvili na eni drevesni vrsti lahko okužijo druge vrste občutljivih dreves (El Gholl in sod., 1996).

Šele pred kratkim so ugotovili, da je T. dryina tudi endofit $\mathrm{v}$ dobu in ceru in njen pomen za drevo ni jasen. Glivo so pogosteje izolirali iz listov propadajočih hras- 
tov kot iz listov zdravih hrastov, v brstih pa so jo pogosteje našli v zdravih hrastih (Gennaro in sod., 2001).

\section{Ukrepi}

Do ugotovitve, da je gliva pogost endofit hrastov je veljalo, da je T. dryina primarni parazit in za zaščito okrasnih hrastov in drugih občutljivih dreves so svetovali zaščito spomladi $\mathrm{z}$ mankozebom (npr. pripravek dithane M-45) (El-Gholl in sod., 1996). Danes bi veljala enaka priporočila kot pri rjavenju hrastovih listov (Discula quercina): zagotoviti čim ustreznejše razmere za rast drevesa.

\section{Viri}

Butin H. 1995. Tree diseases and disorders. Causes, biology and control in forest and Amenity Tress. Oxford, Oxford University Press: 261 str.

El-Gholl N. E., Schubert T. S., Peacock M. E. 1996. Tubakia leaf spot of chestnut. Fla. Dept. of Agric. \& Consumer Services, Division of Plant Industry, Plant Pathology Circular, 375: 2 str.

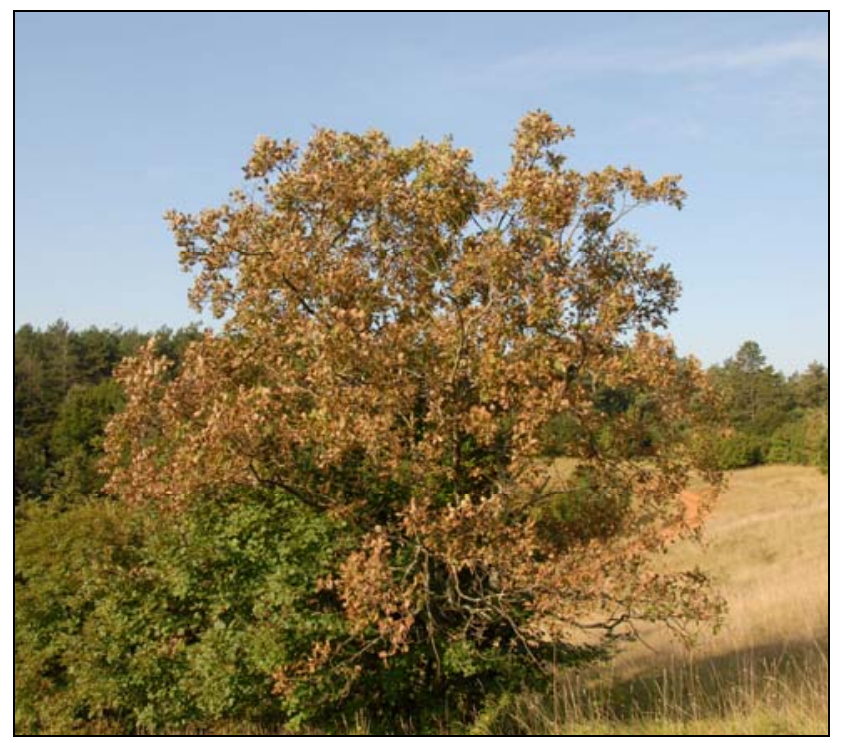

Slika 1: Puhasti hrast $\mathrm{z}$ odmrlim listjem zaradi hrastove listne pegavosti, pod njim je nepoškodovan cer

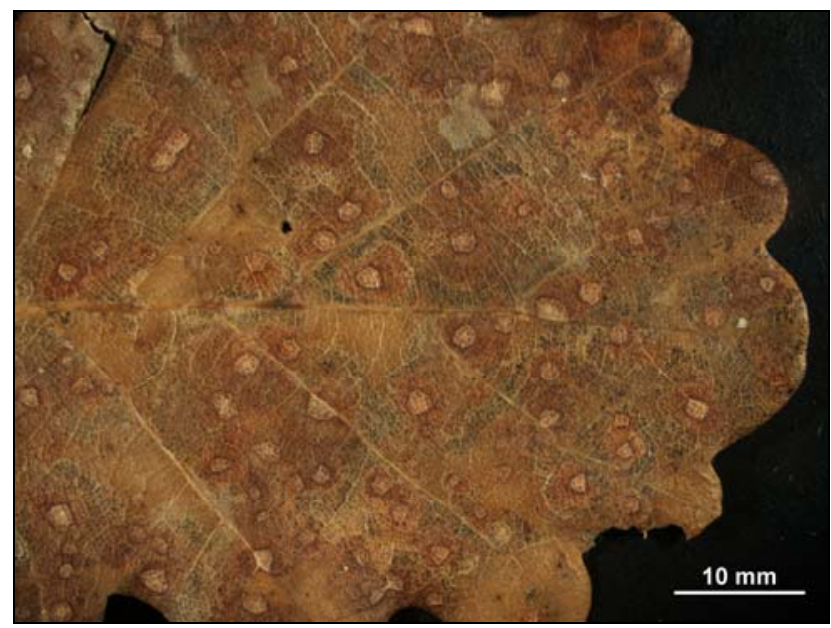

Slika 3: V kolikor je okužb na listu veliko, odmre cel list
Gennaro M., Gonthier P., Nicolotti G., Cellerino G. P. 2001. First report of Tubakia dryina in buds and shoots of Quercus cerris and Quercus robur. Plant Dis., 85: 1289

Jurc D. 2006. Hrasti - Quercus spp.: bolezni listja : Microsphaera alphitoides, Discula quercina, Tubakia dryina. Gozd. vestn., 64, 10: $485-500$

Kirk P.M., Cannon P.F., David J.C., Stalpers J.A. 2001. Dictionary of the fungi. Ninth Edition. CABI Bioscience, CAB International: 655 str.

Proffer T. J. 1990. Tubakia leaf spot. Florida Dpt. Of Agric and Sew. Division of Plant Industry, Plant Pathology Circular, 337: 2 str.

${ }^{1}$ Gozdarski inštitut Slovenije, Večna pot 2, 1000 Ljubljana; 2 Zavod za gozdove Slovenije, Območna enota Sežana, Partizanska 49, 6210 Sežana *dusan.jurc@gozdis.si

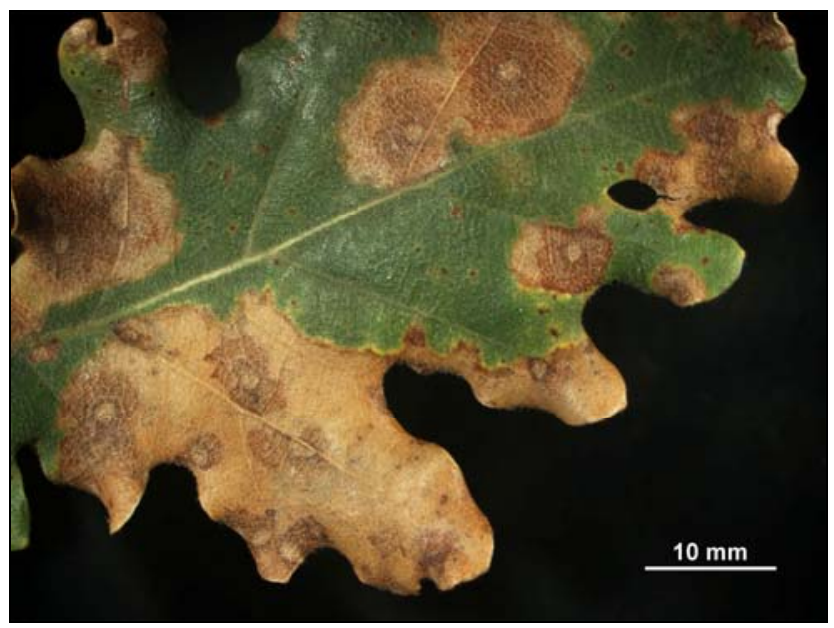

Slika 2: Nekroze se povečujejo in združujejo

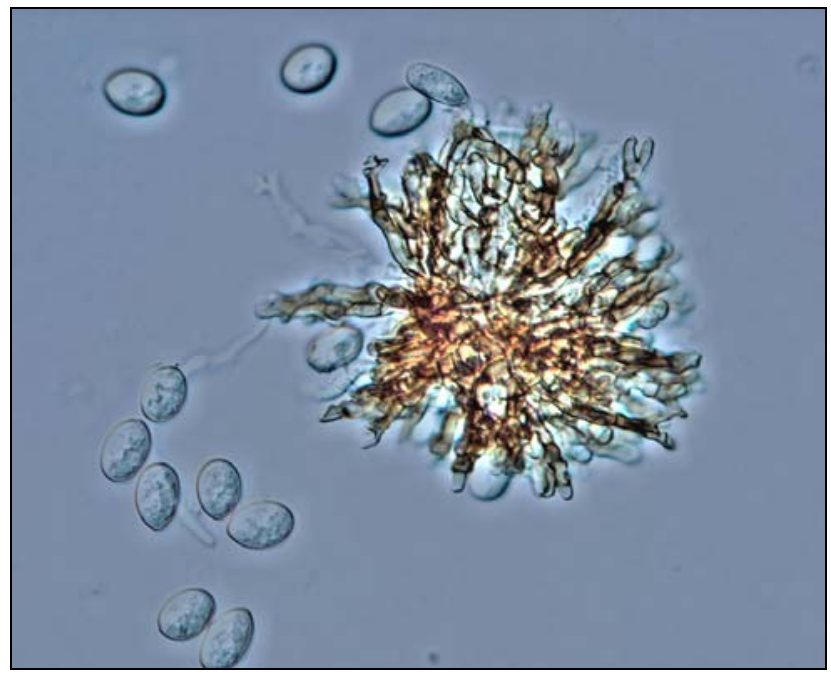

Slika 4: Zrel piknotirij od zgoraj (opazen je ščitek, kolumela se ne vidi) in makrokonidiji 